\title{
A delayed discrimination procedure for rats
}

\author{
JOHN K. PARKINSON and TIMOTHY F. ELSMORE \\ Walter Reed Army Institute of Research, Washington, D.C.
}

\begin{abstract}
A procedure for the rapid training of rats on a delayed conditional discrimination task is described. During a 10-sec sample period, a tone was presented and stimulus lights were either on over both levers or off over both levers. Following a delay, the light over only one of the levers was illuminated, and responding was reinforced on either the lighted or the dark lever, depending on whether the lights over both levers had been on or off during the sample period. With a sample-choice delay of $.01 \mathrm{sec}$, rats acquired this task to a mean of $86 \%$ correct within 9 days of approximately 619 trials per day. Performance over increasing delays was studied, with accuracy falling to chance levels at $32 \mathrm{sec}$. Responding was biased toward the light-on zero-delay trials, but there was no light bias with longer delays. A signal detection analysis of the data showed a smooth relationship between an index of sensitivity $\left(A^{\prime}\right)$ and delay.
\end{abstract}

Evidence is accumulating that short-term memory is not a unitary phenomenon. The fact that some spatial memory problems are solved more rapidly than nonspatial or symbolic memory problems (see Mishkin \& Delacour, 1975, for a brief review) points to at least two different types of short-term memory. Short-term memory in rats typically has been assessed using a variety of spatial memory tests. Examples include the radial arm maze task (Olton \& Samuelson, 1976) and the spatial alternation task (Petrinovich \& Bolles, 1957), both of which test only spatial memory. For a more complete description of the effects of a variety of independent variables upon memory, nonspatial tasks must be assessed as well. In primates, there are several commonly used nonspatial short-term memory tests, one of which is delayed matching to sample (DMTS; D'Amato, 1973). In rodents, however, there are no standard tests for short-term nonspatial memory, although various analogues to primate non-DMTS have been recently described (Aggleton, 1985; Aggleton, Hunt, \& Rawlins, 1986; Jarrard, 1983; Olton \& Feustle, 1981; Rothblat, Hayes, \& Kromer, 1986).

We were searching for a rapidly acquired task that would permit assessment of drug effects on nonspatial memory in the rat. Earlier work in our laboratory using monkeys trained to perform DMTS showed differential effects to anticholinergic compounds in both response rate and accuracy of performance. Similar effects on spatial memory in mice (Levy, Kluge, \& Elsmore, 1983) and in rats (Eckerman, Gordon, Edwards, MacPhail, \& Gage, 1980) have been found using the radial arm maze. There-

In conducting the research described in this report, the investigators adhered to the Guide for the Care and Use of Laboratory Animals, as promulgated by the Committee on Care and Use of Laboratory Animals of the Institute of Laboratory Animal Resources, National Research Council. The views of the authors do not purport to reflect the position of the Department of the Army or the Department of Defense (para 4-3, AR 360-5). Reprints may be obtained from T. F. Elsmore, Department of Medical Neurosciences, Walter Reed Army Institute of Research, Washington, DC 20307-5100. fore, a comparable nonspatial memory model using a rodent species was desirable. In the task described here, rats quickly learned to discriminate the presence or absence of light signaled by a tone cue and to respond to a lighted or dark lever. Over delays of 2 to $32 \mathrm{sec}$, performance dropped to chance.

\section{METHOD}

\section{Subjects}

Twelve experimentally naive male albino rats (Walter Reed SpragueDawley derived), weighing approximately $230 \mathrm{~g}$, were used. The animals lived in the experimental apparatus for the duration of the experiment, and all food was earned under the experimental contingencies, that is, a "closed" economy (Hursh, 1980). The rats were maintained on a 12:12-h light:dark cycle initiated at $2000 \mathrm{~h}$. Water was continuously available from a bottle mounted on the side of the cage.

\section{Apparatus}

The experiment was conducted with 12 two-lever operant chambers (Coulbourn Instruments). The response levers were positioned $6.5 \mathrm{~cm}$ from the floor of the chamber and separated on the front panel by a food-delivery hopper. The Sonalert tone, houselight, stimulus lights, and food solenoid were operated by a DEC PDP/8e computer running the SUPERSKED software system (Snapper \& Kadden, 1973). The chambers were enclosed in sound-attenuating enclosures.

\section{Procedure}

Each 8-h session was initiated at $1030 \mathrm{~h}, 30 \mathrm{~min}$ after light offset. The sample portion of each trial consisted of presentation of a Sonalert tone $(2900 \mathrm{~Hz})$ for $10 \mathrm{sec}$ in conjunction with either the onset of lights over both response levers or the tone and no lights. During sample presentation a response on either lever within $5 \mathrm{sec}$ from the end of the 10-sec period reset the sample presentation time to $5 \mathrm{sec}$. Trial type (i.e., lights vs. no lights) was randomly selected so that each type would occur approximately $50 \%$ of the time.

After sample presentation, a random $(p=0.5)$ selection of either short $(.01 \mathrm{sec})$ or long ( 2 to $32 \mathrm{sec}$ ) delay occurred, during which time the chamber was completely dark. After the delay, the light over one of the response levers was illuminated. A single response within $10 \mathrm{sec}$ by the rat to the lighted lever if the lights had been on during sample presentation, or to the dark lever if no lights had been on during the sample presentation, resulted in the presentation of a single $45-\mathrm{mg}$ food pellet. A correct response or no response within $10 \mathrm{sec}$ initiated a 30 sec intertrial interval (ITI), during which the chamber was completely dark. An incorrect response initiated a 60-sec ITI. A correction proce- 
dure was employed on all trials to reduce lever bias. If the number of pellets accrued on either lever became five more than on the other lever, the probability of that lever's being correct on the subsequent trial was reduced to $25 \%$ until the imbalance was corrected. For acquisition training, all delays were $.01 \mathrm{sec}$.

The delay testing consisted of 2 days at each delay for both an ascending $(2,4,8,16,32 \mathrm{sec})$ and a descending $(32,16,8,4,2 \mathrm{sec})$ series.

\section{RESULTS}

Acquisition performance is presented in Figure 1. The rats rapidly acquired the simultaneous discrimination task, achieving $86 \%$ correct in 9 days of approximately 619 trials per day, with no appreciable difference in accuracy on light and no-light trials by the end of training. When delays were introduced, a significant difference between light and dark trials became apparent. This effect is demonstrated in Figure 2, in which accuracy on both light and no-light trials is shown as a function of delay. Performance on zero-delay trials was not affected by the long delay in effect during that session, so the zero-delay points are pooled across all of the delays. Performance on zerodelay light trials was consistently superior to that on zerodelay dark trials. On long-delay trials, accuracy was significantly better on no-light trials than on light trials, particularly at the longest delays. To obtain quantitative estimates of bias, $B^{\prime \prime}$, a nonparametric signal detection

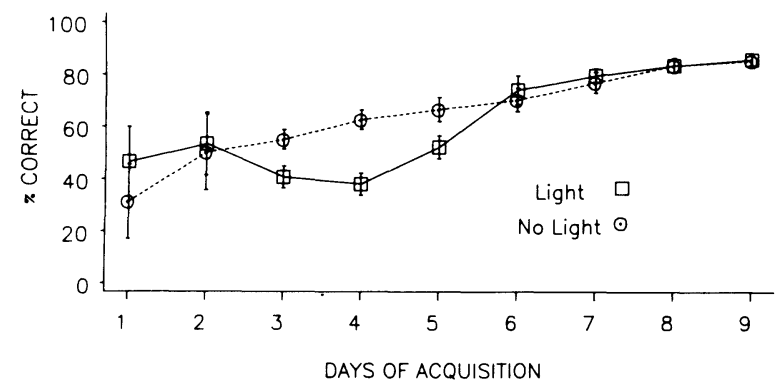

Figure 1. Accuracy of responding on a zero-delay conditional discrimination task on the first nine sessions of exposure to the procedure. Bars represent standard errors of the mean.

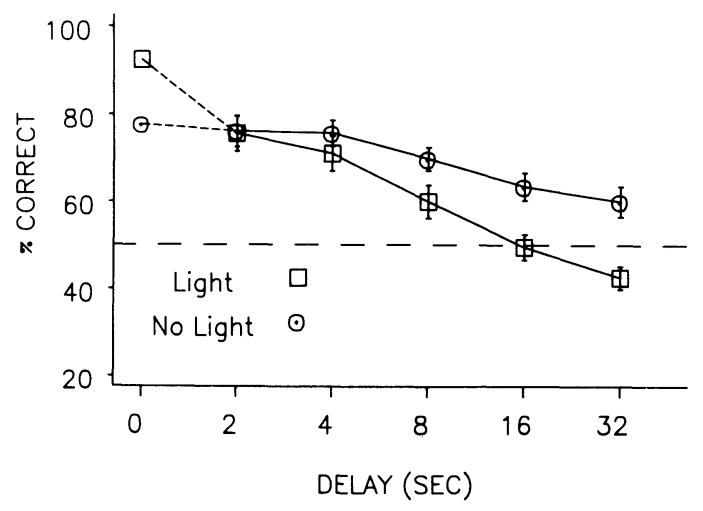

Figure 2. Accuracy of responding for light and no-light trials as a function of delay. Each point represents the mean of 4 days. Bars represent standard errors of the mean.

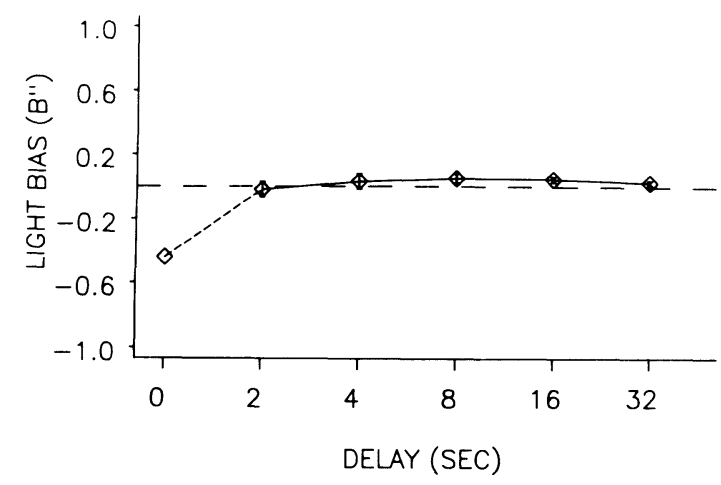

Figure 3. Light bias $\left(B^{\prime \prime}\right)$ as a function of delay. Negative values indicate bias toward responding on the lighted lever. Bars represent standard errors of the mean.

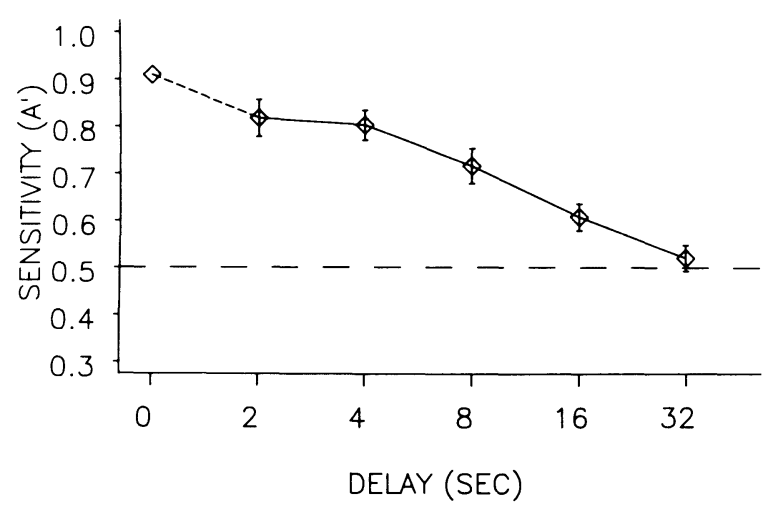

Figure 4. Sensitivity index $\left(A^{\prime}\right)$ as a function of delay. Bars represent standard errors of the mean.

estimator of bias (Grier, 1971; Raslear, 1985), was computed. Figure 3 shows that although there was a consistent bias toward the light on zero-delay trials, there was no bias on nonzero delays. Because of this response bias, we further analyzed the data using the $A^{\prime}$ measure, a nonparametric signal detection estimator of sensitivity, which allows assessment of stimulus control independent of bias.

Figure 4 shows the effect of delay on sensitivity. Performance remained above chance $\left(A^{\prime}=0.5\right)$ at $16 \mathrm{sec}$ ( $t$ test, $n=48, p<.01$ ), but performance fell below chance at $32 \sec (n=48, p>.07)$.

\section{DISCUSSION}

The procedure described in this paper produced rapid acquisition of a relatively complex performance. Two details of this procedure appear to be crucial for producing this rapid acquisition. Normally, the probability of either lever's being correct was .5. At the beginning of training, a correction procedure prevented response perseveration by lowering the probability (from .5 to .1) that a lever would be correct if that lever had produced five pellets more than the other, thus forcing the animals to respond on both levers to obtain food without establishing the win-stay/lose-shift strategy common to more traditional correction procedures. Once the imbalance in pellets obtained on the two levers was corrected, the probability of either lever's being correct reverted to .5 . When the animal was responding reliably on both levers, usually within one to three sessions, an imbalance resulted in a less drastic change (from .5 to .25 ). A second important feature of this procedure 
is the use of a contingency to prevent inappropriate responding. Such contingencies have been shown to be necessary for the establishment of appropriate stimulus control (cf. Herrnstein, 1961). Presses on either lever in the last $5 \mathrm{sec}$ of ITIs, sample presentations, or delay periods reset the time to termination of that time period to $5 \mathrm{sec}$, effectively eliminating all "superstitious" responses, and presumably contributing to the establishment of control by the presence or absence of lights during the sample presentation period. Pilot experiments in which either the correction procedure or the DRO procedure was eliminated resulted in failure of acquisition for $20 \%$ to $50 \%$ of the subjects.

A troublesome feature of the present procedure is the fact that performances were not equivalent on light- and dark-sample trials. Performance was reliably high on zero-delay trials, but with greater accuracy on light trials than on dark trials. This resulted from a bias toward the lighted lever on the zero-delay trials (Figure 3, diamonds). The 2and 4-sec delays showed little difference in accuracy between light and dark trials, whereas the 8- to 32-sec delays showed superior performance on the dark trials. This difference did not represent a reversal of the bias seen on the zero-delay trials, since there was no bias at all when the delay was $2 \mathrm{sec}$ or greater (Figure 3, triangles). One possible explanation for this finding could be retroactive facilitation (Medin, Reynolds, \& Parkinson, 1980), which improved performance on the dark trials. During the delay between the sample presentation and the choice, the chamber is dark, which could facilitate recall of a dark sample.

Although the existence of response bias makes performance resulting from this procedure somewhat difficult to analyze, the procedure provides useful data on both quantitative and qualitative measures of performance. Delayed trials provide a measure of discrimination, but delays less than $2 \mathrm{sec}$ are not recommended because of the response bias. Short delays, if needed, may be compared with longer delays if a signal detection analysis procedure is used. Regardless of the mechanism, with longer delays, a nonspatial short-term memory seems to be involved. Data generated by this procedure should be useful in comparisons with more traditional spatial memory procedures that have been used in rodents, and with comparisons of rodent and primate memory data.

\section{REFERENCES}

AGgleton, J. P. (1985). One-trial object recognition by rats. Quarterly Journal of Experimental Psychology, 37B, 279-294.

Aggleton, J. P., Hunt, P. R., \& Rawlins, J. N. P. (1986). The effects of hippocampal lesions upon spatial and non-spatial tests of working memory. Behavioral Brain Research, 19, 133-146.

D'Amato, M. R. (1973). Delayed matching and short-term memory in monkeys. In G. Bower (Ed.), The psychology of learning and moti- vation: Advances in research and theory (Vol. 7, pp. 227-269). New York: Academic Press.

Eckerman, D. A., Gordon, W. A., Edwards, J. D., MacPhail, R. C., \& GAGE, M. I. (1980). Effects of scopolamine, pentobarbital, and amphetamine on radial maze performance in the rat. Pharmacology, Biochemistry \& Behavior, 12, 595-602.

Grier, J. B. (1971). Nonparametric indexes for sensitivity and bias: Computing formulas. Psychological Bulletin, 75, 257-262.

HerRnstein, R. J. (1961). Relative and absolute strength of response as a function of frequency of reinforcement. Journal of the Experimental Analysis of Behavior, 4, 267-272.

HURSH, S. R. (1980). Economic concepts for the analysis of behavior. Journal of the Experimental Analysis of Behavior, 34, 219-238.

JARRARD, L. E. (1983). Selective hippocampal lesions and behavior: Effects of kainic acid lesions on performance of place and cue tasks. Behavioral Neuroscience, 97, 873-889.

Levy, A., Kluge, P. B., \& ElSmore, T. F. (1983). Radial arm maze performance of mice: Acquisition and atropine effects. Behavioral \& Neural Biology, 39, 229-240.

Medin, D. L., Reynolds, T. J., \& Parkinson, J. K. (1980). Stimulus similarity and retroactive interference and facilitation in monkey short-term memory. Journal of Experimental Psychology: Animal Behavior Processes, 6, 112-125.

Mishkin, M., \& Delacour, J. (1975). An analysis of short-term visual memory in the monkey. Journal of Experimental Psychology: Animal Behavior Processes, 1, 326-334.

Olton, D. S., \& Feustle, W. A. (1981). Hippocampal function required for nonspatial working memory. Experimental Brain Research, 41, 380-389.

Olton, D. S., \& SAmUelson, R. J. (1976). Remembrances of places past: Spatial memory in rats. Journal of Experimental Psychology: Animal Behavior Processes, 2, 97-116.

Petrinovich, L., \& Bolles, R. C. (1957). Delayed alternation: Evidence for symbolic processes in the rat. Journal of Comparative \& Physiological Psychology, 50, 363-365.

Raslear, T. G. (1985). Perceptual bias and response bias in temporal bisection. Perception \& Psychophysics, 38, 261-268.

Rothblat, L. A., Hayes, L. L., \& Kromer, L. F. (1986). Effects of septo-hippocampal damage on spatial and non-spatial tests of working memory. Society for Neuroscience Abstracts, p. 743.

SNAPPER, A. G., \& KADDEN, R. M. (1973). Time-sharing in a small computer based on a behavioral notation system. In B. Weiss (Ed.), Digital computers in the behavioral laboratory (pp. 41-97). New York: Appleton-Century-Crofts.

(Manuscript received March 26, 1988.) 